Research Article

\title{
Laparoscopic assisted anorectoplasty in children: a prospective study
}

\author{
Sanjay Raina ${ }^{1}$, Beena Jad ${ }^{2}$, Vijayendra Kumar ${ }^{1}$, S. P. Sharma ${ }^{1}$, Nilay Kumar ${ }^{1}$
}

${ }^{1}$ Department of Paediatric Surgery, BHU, Varanasi, India
${ }^{2}$ Department of Microbiology, GMC, Jammu, India

Received: 14 October 2015

Revised: 01 December 2015

Accepted: 16 December 2015

\section{*Correspondence:}

Dr. Sanjay Raina,

E-mail: sanjay.raina315@gmail.com

Copyright: () the author(s), publisher and licensee Medip Academy. This is an open-access article distributed under the terms of the Creative Commons Attribution Non-Commercial License, which permits unrestricted non-commercial use, distribution, and reproduction in any medium, provided the original work is properly cited.

\section{ABSTRACT}

Background: Anorectal malformations are a spectrum of congenital defects that continue to represent a significant challenge for the paediatric surgeon. Development of minimally invasive surgery has probably been the biggest revolution in surgical practice in last two decades, which has gone through a period of rapid development during last 10 years; one of such changing procedure is LAARP for ARM. The aim of this study is to evaluate the clinical and functional outcomes in children with anorectal malformation treated by LAARP.

Methods: From Sep.2012 to June 2014, 16 patients with intermediate and high imperforate anus underwent LAARP. Inclusion criteria were children with ARM, age >3 months, stage I sigmoid colostomy, with no associated morbid anomaly, Operative procedure followed was that given by Georgeson KE (2000).

Results: 16 cases were included in this study out of which males were $87.5 \%$. The most common ARM type was rectobulbar fistula (50\%). The mean operative time was $2.75 \mathrm{hrs}$ approx. and mean blood loss 24 ml approx. Conversion rate to APPT was $25 \%$. The mean length of hospital stay was shorter ( 8 day's approx). Few postoperative complications were mucosal prolapse $6.25 \%$, stenosis $12.5 \%$, and peritoneal contamination with faecal matter $12.5 \%$, temporary neurogenic bladder $12.5 \%$.

Conclusions: Laparoscopically assisted anorectal pull-through has advantages, including shorter hospital stay, minimal blood loss and better functional outcome. Satisfactory rectal continence can be achieved in children with imperforate anus after LAARP. Shorter dissection of rectum in the intra-abdominal space may be helpful in preventing rectal mucosal prolapse.

Keywords: Laparoscopic assisted anorectoplasty, Anorectal malformations, Posterior sagittal anorectoplasty, Abdomino-perineal pull through

\section{INTRODUCTION}

The development of minimally invasive surgery has probably been the biggest revolution in surgical practice in last two decades, which has gone through a period of rapid development during last 10 years. These minimal access techniques have changed the approach to many surgical procedures; one of such changing procedure is laparoscopically assisted anorectoplasty (LAARP) in children which is receiving widespread interest from many general and paediatric surgeons.

Anorectal malformations (ARMs) are a spectrum of congenital defects that continue to represent a significant challenge for the paediatric surgeon. These defects are frequently associated with life-long debilitating sequelae such as faecal and urinary incontinence and sexual inadequacy. ${ }^{1}$ ARMs occur in approximately 1 in 4000 to 5000 live births, with imperforate anus being the most common variant. ${ }^{2}$ 
Over the past several years, techniques have evolved in the repair of these, starting with the abdominoperineal pull-through, sacroperineal pull-through and posterior sagittal anorectoplasty (PSARP). ${ }^{3}$ PSARP is current standard of surgical care for ARMs. This operation provides excellent exposure of the anatomy and the precise placement of the distal rectum within the muscle complex. ${ }^{4}$

Though this approach is cosmetically satisfactory, results regarding continence have been inconsistent. Additionally, the lack of a normally functioning internal sphincter makes the attainment of complete faecal continence difficult to achieve. The deranged motility of the recto-sigmoid colon in these patients adds complexity to successfully restoring faecal continence. The desire to preserve the sphincters, place sensate skin within the control of the sphincters, and shorten recovery has led to the development of this minimally invasive surgical technique LAARP. ${ }^{5}$ Benefits of the procedure include lack of division of the muscle complex, no need for laparotomy, decreased pain to the patient, and potentially less perineal wound complications. Additional advantages include repair of associated defect at operation (i.e., hernia, identification and repair of cryptorchid testes), superior pelvic visualization not possible with open surgery, and anatomic placement of the pull-through bowel by identifying the central portion of the puborectalis from inside and the external anal sphincter from outside the patient. ${ }^{6}$ However, long term follow-up is necessary to compare the benefits of LAARP against PSARP. $^{7}$

In the background of this, the present study was undertaken to evaluate whether laparoscopy is less invasive and achieves better functional results and to establish it as an alternative to conventional surgery.

\section{METHODS}

A prospective study conducted from September 2012 to September 2014 in Department of Paediatric Surgery IMS, BHU. Approval was obtained from ethical committee of university. Patients up to 2 years of age group, coming to surgical ward through surgical outpatient department of SS Hospital Varanasi, admitted as a case of anorectal malformation.

\section{Criteria for selection of cases}

\section{Inclusion criteria}

1. Patients with anorectal malformation willing for surgery by laparoscopic technique and fit for general anaesthesia.

2. Age $>3$ months.

3. Stage I sigmoid colostomy.

4. Intermediate and high types ARM.

5. No other associated morbid anomaly.

\section{Exclusion criteria}

1. ARM with associated syndrome.

2. Cloaca type ARM.

3. Low type ARM.

4. Associated morbid anomaly.

5. Age $<3$ months.

\section{Procedure}

A Standard proximal sigmoid colostomy is performed in the newborn. After 3 months patient is posted for laparoscopic anorectoplasty, Patient is positioned in lithotomy at the end of table, a bladder catheter is placed. Pneumoperitoneum to a pressure of 8 to $12 \mathrm{~cm} \mathrm{H}_{2} \mathrm{O}$ is established using a Veress needle inserted at umbilicus. This incision is then used for placement of a $5 \mathrm{~mm}$ trocar for umbilical port. A $3 \mathrm{~mm}$ trocar is placed in the right anterior axillary line just below liver. A $3 \mathrm{~mm}$ trocar is placed in right anterior axillary line just above anterior superior iliac spine.

Laparoscopic rectal dissection is begun at the peritoneal reflection. Using hook cautery, the distal mesorectum is divided and bipolar scissor cautery dissection continued anteriorly and laterally on the rectal wall. As the rectum tapered distally, the fistula to the urethra or vagina is identified, cauterized at the insertion on the posterior urethra, and sharply divided and not ligated. When the bowel is retracted cephalad out of the pelvis, this dissection allows examination of the underlying levator muscles in the pelvic floor. When present, the pubococcygeus muscle is visualized clearly. When there is insufficient muscle mass to clearly identify pubococcygeus, the midline is identified based on the position of the distal end of the divided fistula and urethra. Externally, the anal area of the perineum is mapped. This area of maximal contraction and ventrocephalad elevation of the perineum is noted. The anterior, lateral and posterior limits of this anal area are marked with sutures, and $1 \mathrm{~cm}$ vertical midline incision made in the perineum at the site of the proposed anal orifice. The intrasphincteric plane is dissected bluntly from below to the level of the levator sling using laparoscopic backlighting. A radially expanding trocar over a Veress needle is passed through the intrasphincteric plane and advanced between the 2 bellies of the pubococcygeus muscle in the midline using laparoscopic guidance, just posterior to the urethra. If the needle is inaccurately passed to either side of the midline, it gets readily apparent because of laparoscopic surveillance and easily corrected before radial dilation of the tract. The tract is then dilated radially to $10 \mathrm{~mm}$ and the divided rectal fistula grasped and pulled onto the perineum while removing the trocar. No attempt is made to suture rectum to the levator musculature. The anastomosis between rectum and anus is completed with interrupted 3-0 polyglycolic acid suture. The rectum is retracted cephalad laparoscopically. ${ }^{8}$ 


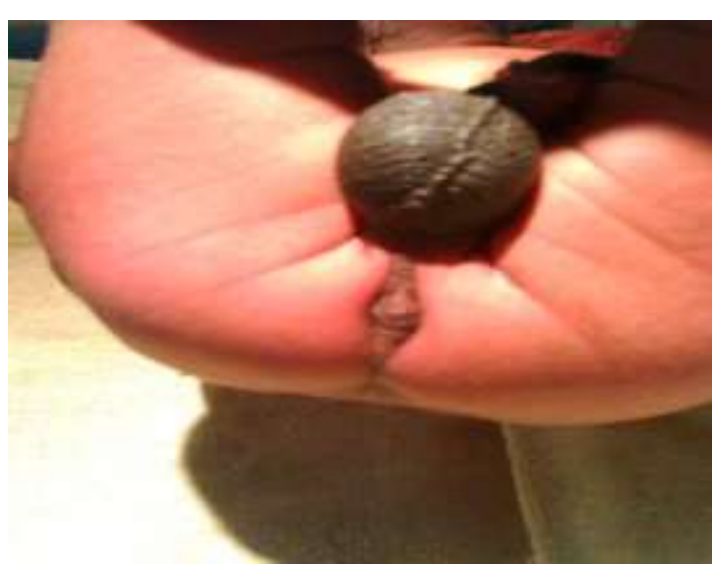

Figure 1: Neonate with anorectal malformation.

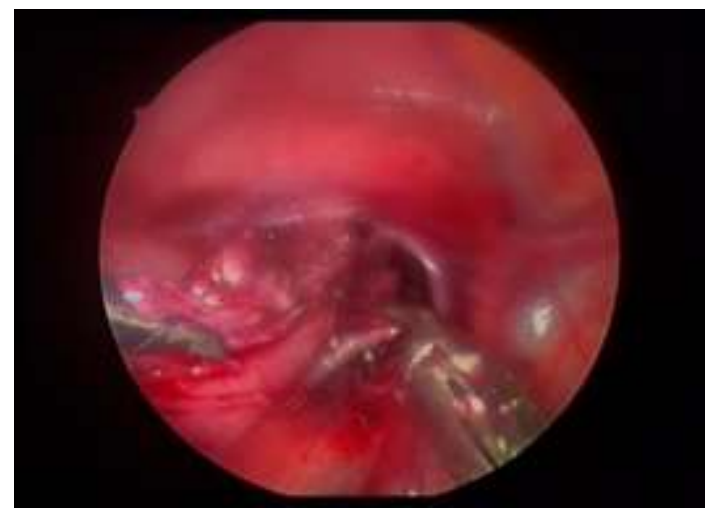

Figure 2: Fistula to the prostatic urethra seen.

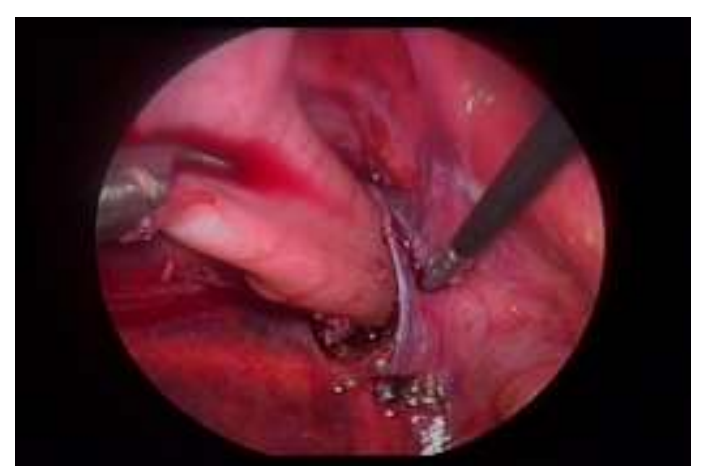

Figure 3: Rectal fistula pulled onto the perineum.

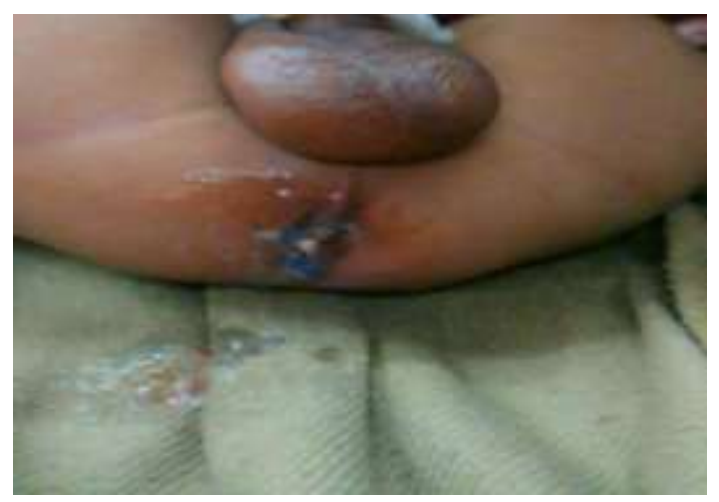

Criteria for evaluation of this technique as follows;

1. Stay at hospital.

2. Duration of surgery.

3. Per-op parameters:

a. Injury to vas.

b. Injury to urethra.

c. Injury to gut.

d. Blood loss.

e. Transfusion required.

f. Conversion rate.

g. Peritoneal contamination.

4. Post operative complications:

i. Mucosal prolapse.

ii. Anal stenosis.

iii. Port site hernia.

iv. Port site sepsis.

v. Neurogenic bladder.

vi. Incontinence.

vii. Functional outcome.

viii. Morbidity.

\section{RESULTS}

Table 1: Distribution of cases according to age group $(n=16)$.

\begin{tabular}{|lll|}
\hline Age group & $\begin{array}{l}\text { Number of } \\
\text { cases }\end{array}$ & $\begin{array}{l}\% \text { of } \\
\text { cases }\end{array}$ \\
\hline $3-9$ months & 5 & $31.25 \%$ \\
\hline $10-15$ months & 6 & $37.50 \%$ \\
\hline $16-22$ months & 5 & $31.25 \%$ \\
\hline Total & 16 & 100.00 \\
\hline
\end{tabular}

Distribution of patients was done in the three age groups. Group 1 of 3 to 9 months old comprised 5 patients (31.25\%). Group 2 of 10 to 15 months old comprised 6 patients $(37.50 \%)$ and Group 3 of 16 to 22 months old comprised 5 patients $(31.25 \%)$. Almost equal number of patients was observed in all age groups, with 10 to 15 months age group showing slight predominance.

Table 2: Distribution of cases according to sex.

\begin{tabular}{|lll|}
\hline Sex & $\begin{array}{l}\text { Number } \\
\text { of cases }\end{array}$ & $\begin{array}{l}\text { \% of } \\
\text { cases }\end{array}$ \\
\hline Male & 14 & $87.50 \%$ \\
\hline Female & 2 & $12.50 \%$ \\
\hline Total & 16 & 100.00 \\
\hline
\end{tabular}

Majority of patients with anorectal malformations were male $14(87.50 \%)$, while there were only $2(12.50 \%)$ female patients in the present study.

Mean weight of the study group was 7.68 \pm 2.67 (range 512) $\mathrm{kg}$, with equal number of patients $(50 \%)$ in each, 5 to $7 \mathrm{~kg}$ and 8 to $12 \mathrm{~kg}$ weight groups respectively.

Figure 4: Completed anorectoplasty. 
Table 3: Distribution of cases according to body weight.

\begin{tabular}{|llc|}
\hline Body weight & Number of cases & \% of cases \\
\hline $5-7 \mathrm{~kg}$ & 8 & $50 \%$ \\
\hline $8-12 \mathrm{~kg}$ & 8 & $50 \%$ \\
\hline Total & 16 & $100 \%$ \\
\hline
\end{tabular}

Table 4: Distribution of $\mathrm{ARM}$ with respect to site of fistula.

\begin{tabular}{|lll|}
\hline ARM defect & Number of cases & \% of cases \\
\hline Rectoprostatic fistula & 6 & $37.50 \%$ \\
\hline Rectobulbar fistula & 8 & $50 \%$ \\
\hline Rectovaginal fistula & 2 & $12.50 \%$ \\
\hline Total & 16 & $100 \%$ \\
\hline
\end{tabular}

The most common ARM defect observed in the study was rectobulbar fistula, 8 patients $(50 \%)$, followed by rectoprostatic fistula, 6 patients $(37.50 \%)$ and rectovaginal fistula, 2 patients $(12.50 \%)$.

Table 5: Operative data of LAARP.

\begin{tabular}{|lc|}
\hline Total cases & 16 \\
\hline $\begin{array}{l}\text { Mean operative time } \\
\text { (hours) }\end{array}$ & $2.75 \pm 0.51$ (range 2-3.5) \\
\hline Mean blood loss $(\mathrm{ml})$ & $24.37 \pm 13.76$ (range 10-50) \\
\hline $\begin{array}{l}\text { Conversion to open } \\
\text { surgery }\end{array}$ & $4(25 \%)$ \\
\hline $\begin{array}{l}\text { Mean hospital stay } \\
\text { (days) }\end{array}$ & $8.12 \pm 3.59$ (range 5-14) \\
\hline Blood Transfusion & $6(37.50 \%)$ \\
\hline
\end{tabular}

In the present study mean operative time was 2.75 hours and mean blood loss was $24.37 \mathrm{ml}$. Conversion rate was $25 \%$, with two cases each of rectobulbar fistula and rectoprostatic fistula. Mean hospital stay of patients was $8.12 \pm 3.59$ (range 5-14) days, while $37.5 \%$ patients needed blood transfusion.

Table 6: Post-operative data of LAARP.

\begin{tabular}{|lll|}
\hline Complication & Number of cases & $\%$ of cases \\
\hline Mucosal prolapsed & 1 & $6.25 \%$ \\
\hline Urethral injury & 0 & $0 \%$ \\
\hline Anal stenosis & 2 & $12.50 \%$ \\
\hline Peritoneal contamination & 2 & $12.50 \%$ \\
\hline $\begin{array}{l}\text { Temporary neurogenic } \\
\text { bladder }\end{array}$ & 2 & $12.50 \%$ \\
\hline Morbidity & 5 & $31.25 \%$ \\
\hline Conversion & 4 & $25 \%$ \\
\hline Vas injury & 0 & $0 \%$ \\
\hline Total & 16 & $100 \%$ \\
\hline
\end{tabular}

Postoperative complications observed were mucosal prolapse in 1 patient $(6.25 \%)$, anal stenosis in 2 patients $(12.50 \%)$, peritoneal contamination in 2 patients $(12.5 \%)$, temporary neurogenic bladder in 2 patients (12.50\%). Conversion to open conventional surgery was done in 4 patients $(25 \%)$. Overall morbidity was seen in 5 patients $(31.25 \%)$.

Table 7: Functional outcome of patients according to Kelly's clinical score.

\begin{tabular}{|c|c|c|}
\hline $\begin{array}{l}\text { Kelly's clinical } \\
\text { score }\end{array}$ & Number of cases & $\%$ of cases \\
\hline K3 & 4 & $25 \%$ \\
\hline K4 & 8 & $50 \%$ \\
\hline K5 & 4 & $25 \%$ \\
\hline Total & 16 & $100 \%$ \\
\hline
\end{tabular}

In the present study, functional outcome of patients was defined according to Kelly's clinical score. The information concerning fecal incontinence and fecal staining was gained from children's parents and digital rectal examination. Mean KCS was observed to be 3.75 0.68 . Half of the patients $(50 \%)$ were assigned Kelly's clinical score of 4 , followed by $25 \%$ with K5 and $25 \%$ with K3. Constant staining/smearing and soiling/accidental defection after LAARP were observed in 2 patients each respectively. Also, 1 patient each had constant bout of constipation and diarrhoea. 8 patients were observed with occasional staining/smearing and 6 patients with soiling or accidental defection. 4 patients had occasional constipation and 1 patient had diarrhoea.

Table 8: Functional outcome based on Kelly's clinical score.

\begin{tabular}{|llcl|}
\hline FO & None & Occasional & Constant \\
\hline Staining/smearing & 6 & 8 & 2 \\
\hline $\begin{array}{l}\text { Soiling/accidental } \\
\text { defecation }\end{array}$ & 8 & 6 & 2 \\
\hline Constipation & 11 & 4 & 1 \\
\hline Diarrohea & 1 & 1 & 1 \\
\hline
\end{tabular}

Table 9: Strength of puborectalis on DRE.

\begin{tabular}{|lll|}
\hline Strength of puborectalis & \\
\hline Strong & Weak & None \\
\hline 7 & 6 & 3 \\
\hline
\end{tabular}

On digital rectal examination seven patients $43.75 \%$ had strong anal sphincteric tone; six patients $(37.51 \%)$ had weak anal sphincteric tone. Three patients $(18.75 \%)$ had no anal sphincteric tone.

\section{DISCUSSION}

The main objective of any surgery for ARMs is to achieve a socially accepted quality of life as well as having the affected children develop into healthy adults. ${ }^{9}$ Therefore, the long-term results should be evaluated in terms of bowel function, urinary function, sexual function, and social activity. ${ }^{10}$ 
Over the past several years, techniques have evolved in the repair of high and intermediate anorectal malformations (ARMs), starting with the abdominoperineal pull-through, sacroperineal pullthrough, and posterior sagittal anorectoplasty (PSARP) and now moving toward the recently reported laparoscopically assisted anorectal pull-through (LAARP) procedure. ${ }^{3}$

Ever since laparoscopic-assisted anorectal pullthrough(LAARP) procedure for repair of high imperforate anus has been described, the role of laparoscopy in management of ARMs is expanding ${ }^{8}$.This is because of many perceived benefits of the technique, including minimal perineal dissection, excellent visualization of the rectal fistula and surrounding structures, and preservation of the distal rectum with accurate placement of the rectum within the levatorani and external anal sphincter muscle complex. ${ }^{3}$

Taking all these facts in consideration, the present prospective study was conducted for a period of two years in the Department of Pediatric Surgery IMS, BHU. Sixteen patients with anorectal malformation of intermediate/high type ARM with no other associated morbid anomaly willing for surgery by laparoscopic technique were taken up as subjects of this study.

Mean age observed in present study was 11.2 months (range 3-22). When compared with other studies Tong et al observed mean age of 33 patients undergoing LAARP to be 5.3 (range 3-10) months. ${ }^{11}$ Jung et al in their study of 25 male subjects, who underwent LAARP for rectourethral or rectovesical fistula, observed the mean age to be 2.7 months. ${ }^{12}$

Table 10: Comparison of age with different studies.

\begin{tabular}{|c|c|}
\hline Tong et $\mathrm{al}^{11}$ & 3-10 months \\
\hline De Vos $C^{13}$ & $2-18$ months \\
\hline Jung et $\mathrm{al}^{12}$ & 2.7 months \\
\hline Present study & 3-22 months \\
\hline
\end{tabular}

Mean age is higher in present study when compared to other studies since most of laparoscopic anorectoplasties are done as second stage procedure following a protective colostomy in neonatal period. Moreover due to poor socioeconomic status patients come late in follow-up. Also Primary LAARP is technically difficult in neonates although such procedures have been tried a few centers with success.

In the present study, male patients $(87.50 \%)$ dominated the studied group with a male:female ratio of $7: 1$. Tong et al observed male dominance in their study of 33 patients with male:female ratio of 9:2. ${ }^{11}$ Stephens and Smith and Rintala et al also reported that in Western communities there is a male preponderance, with 55 to $70 \%$ of patients in larger series being male. ${ }^{14,15}$ The more severe malformations tend to be more common in male patients.
Table 11: Comparison of sex (M/F).

\begin{tabular}{|c|c|}
\hline Stephens and Smith ${ }^{14}$ & $7: 3$ \\
\hline Rintala et $\mathrm{al}^{15}$ & 7.3 \\
\hline Tong et $\mathrm{al}^{11}$ & $9: 2$ \\
\hline De $\operatorname{Vos} C^{13}$ & $1.6: 1$ \\
\hline Present study) & $7: 1$ \\
\hline
\end{tabular}

It has been observed that there is a male preponderance, with 55 to $70 \%$ of patients in larger series being male. In present study $87.50 \%$ were male. High incidence in present study could be due to fact that commonest type in female is vestibular type and they do present late in early infancy, moreover cloacal type were excluded in our study which could be an additional factor.

Mean weight observed in present study was $7.68 \pm 2.67$ $\mathrm{kgs}$ which is similar to study of Tong et al who observed mean body weight of $6.8 \pm 1.4 \mathrm{kgs}$ in his study. ${ }^{11}$ Jung et al observed mean body weight of $5.7 \pm 1.6 \mathrm{kgs} .^{12}$

Table 12: Comparison of mean weight.

\begin{tabular}{|ll|}
\hline Tong et $\mathrm{al}^{11}$ & $6.8 \pm 1.4 \mathrm{kgs}$ \\
\hline Jung et $\mathrm{al}^{12}$ & $5.7 \pm 1.6 \mathrm{kgs}$ \\
\hline Present study & $7.68 \pm 2.67 \mathrm{kgs}$ \\
\hline
\end{tabular}

Weight of more than 6 kilograms was found in both the studies. It is technically easier to do in infants than neonates, so at most centers it is done when infant weighs more than six kgs.

The most common ARM defect observed in the present study was rectobulbar fistula $(50 \%)$, followed by rectoprostatic fistula $(37.50 \%)$ and rectovaginal fistula $(12.50 \%)$. De Vos et al, observed in his study rectoprostatic fistula $(7.3 \%)$, rectobulbar fistula $(48 \%)$, rectovesical fistula $(2.43 \%)$ and rectovaginal fistula $(14.63 \%) .{ }^{13}$ Tong et al, ${ }^{11}$ reported most common type of imperforate anus as rectoprostatic fistula (66.67\%), followed by rectobulbar fistula $(18.18 \%)$, rectovaginal fistula $(12.12 \%)$ and rectovesical fistula $(3.03 \%)$. Iwanaka et al found in their study that the most common type of ARM in male patients was prostatic (30.6\%), followed by rectourethral and bulbar. ${ }^{16}$ Rectovaginal ARM was most common in females, occurring in $8.9 \%$ patients $(8.9 \%)$, followed by cloacal and vestibular. Jung et $a{ }^{12}$ in their study of 25 male subjects observed the most common type of anorectal malformation was rectoprostatic urethral fistula (64\%), followed by rectovesical fistula (24\%)and rectobulbar fistula (12\%).

In present study recto bulbar fistula has been the commonest type, whereas recto prostatic fistulas have been found to be more common in other studies. Statistical variation has been observed in most studies regarding type of fistula this variation could be explained due to smaller sample size and short study period. 
Geographical variation can also result in statistical differences.

Table 13: Comparison of ARM defects with respect to site of fistula.

\begin{tabular}{|lllll|}
\hline Study & $\begin{array}{l}\text { Recto } \\
\text { prostatic }\end{array}$ & $\begin{array}{l}\text { Rectob } \\
\text { ulbar }\end{array}$ & $\begin{array}{l}\text { Recto } \\
\text { vesical }\end{array}$ & $\begin{array}{l}\text { Recto } \\
\text { Vagin } \\
\text { al }\end{array}$ \\
\hline $\begin{array}{l}\text { Iwanaka et } \\
\text { al }^{16}\end{array}$ & $30.6 \%$ & - & $8.9 \%$ & - \\
\hline Tong et al & & & & \\
\hline $\begin{array}{l}\text { De Vos C et } \\
\text { al }^{13}\end{array}$ & $7.3 \%$ & $48 \%$ & $2.43 \%$ & $14.63 \%$ \\
\hline Jung et al & $64 \%$ & $12 \%$ & $24 \%$ & - \\
\hline Present study & $37.50 \%$ & $50 \%$ & $0 \%$ & $12.5 \%$ \\
\hline
\end{tabular}

In the present study, mean operative time was $2.75 \pm 0.35$ (range 2-3.5) hours and mean blood loss was 24.37 (range 10-50) $\mathrm{ml}$ with $37.5 \%$ patients needing blood transfusion. Conversion rate to open conventional surgery was $25 \%$, while mean hospital stay of patients was $8.12 \pm 2.3$ (range 5-14) days, transfusion was required in 6 $(37.50 \%)$ patients. Tong et al, ${ }^{11}$ reported mean operative time for patients as $112.5 \pm 12.4$ minutes and mean blood loss as $10.2 \pm 5.8 \mathrm{ml}$, while mean length of hospital stay was $11.3 \pm 1.2$ days with no conversions to laparotomy. Jung et al, reported in their study the median length of postoperative hospitalization was 8 days (range: 6 - 42 days) and the mean operation time was $3.9 \pm 1.3$ hours. ${ }^{12}$ The operation time was longest in the first LAARP patient. Ming AX gave a comparison study showing mean operative time of LAARP $1.62 \pm 0.40$, Hospital stay was significantly shorter $5.8 \pm 0.6$ days. ${ }^{17}$

Table 14: Comparison of mean operative time, mean blood loss, conversion and hospital stay.

\begin{tabular}{|lllll|}
\hline & MOT & MB & C & $\begin{array}{l}\text { HS } \\
\text { (days) }\end{array}$ \\
\hline $\begin{array}{l}\text { Tong et } \\
\text { al }^{11}\end{array}$ & $\begin{array}{l}1.5 \pm 0.2 \\
\text { hours }\end{array}$ & $\begin{array}{l}10.2 \pm 5.8 \\
\mathrm{ml}\end{array}$ & $0 \%$ & $11.3 \pm 1.2$ \\
\hline $\begin{array}{l}\text { Jung et } \\
\mathrm{al}^{12}\end{array}$ & $\begin{array}{l}3.9 \pm 1.3 \\
\text { hours }\end{array}$ & - & - & 8 \\
\hline $\begin{array}{l}\text { Ming } \\
\mathrm{AX}^{17}\end{array}$ & $\begin{array}{l}1.62 \pm 0.4 \\
\text { hours }\end{array}$ & - & - & $5.8 \pm 0.6$ \\
\hline $\begin{array}{l}\text { Present } \\
\text { study }\end{array}$ & $\begin{array}{l}2.75 \pm 0.3 \\
5 \text { hours }\end{array}$ & $\begin{array}{l}24.37 \pm 13.76 \\
\mathrm{ml}\end{array}$ & $25 \%$ & $\begin{array}{l}\text { 25.12 } \\
3\end{array}$ \\
\hline
\end{tabular}

Mean operative time and mean blood loss has been found more in present study compared to study of Tong et al, and Ming AX although similar to Jung et al, study. ${ }^{11,12,17}$ Conversion rate has been found higher as compared to other studies. This could be attributed to learning curve and due to reason that laparoscopic anorectoplasty has been done for first time in our institute and further improvement in our skill is needed to match results of other studies.
Postoperative complications observed were mucosal prolapse $(6.25 \%)$, temporary neurogenic bladder, anal stenosis, peritoneal contamination $(12.50 \%)$. Conversion rate $(25 \%)$ with overall morbidity of $(31.25 \%)$ was observed. Tong et al, ${ }^{11}$ reported that $3(9.09 \%)$ patients encountered postoperative mucosal prolapse after undergoing LAARP. However, there were no severe postoperative complications, such as incontinence or urethral injury. Jung et al, ${ }^{12}$ reported in their study that the immediate postoperative complications occurred in only $12 \%$ patients, including a urinary tract infection in a vesicoureteral reflux patient. De Vos $2011^{13}$ in his study observed mucosal prolapse in $10 \%$ of patients, anal stenosis in $15 \%$, and peritoneal contamination in $14 \%$ with conversion rate of $10 \%$ and urethral injury in $5 \%$ of patients.

\section{Table 15: Comparative analysis of post-op complication.}

\begin{tabular}{|llll|}
\hline & $\begin{array}{l}\text { De Vos } \\
\mathbf{2 0 1 1 ^ { 1 3 }}\end{array}$ & $\begin{array}{l}\text { Ming et } \\
\text { al, 2014 }\end{array}$ & $\begin{array}{l}\text { Present } \\
\text { study }\end{array}$ \\
\hline Mucosal Prolapse & $10 \%$ & $7.5 \%$ & $6.25 \%$ \\
\hline Urethral injury & $5 \%$ & - & $0 \%$ \\
\hline Anal stenosis & $15 \%$ & - & $12.50 \%$ \\
\hline $\begin{array}{l}\text { Peritoneal } \\
\text { contamination }\end{array}$ & $5 \%$ & - & $12.50 \%$ \\
\hline $\begin{array}{l}\text { Temporary } \\
\text { neurogenic bladder }\end{array}$ & - & - & $12.50 \%$ \\
\hline Morbidity & - & $12.5 \%$ & $31.25 \%$ \\
\hline Conversion & $10 \%$ & - & $25 \%$ \\
\hline Vas injury & $5 \%$ & - & $0 \%$ \\
\hline
\end{tabular}

Compared to other studies incidence of mucosal prolapse, anal stenosis and peritoneal contamination is similar to present study, however higher rates of temporary neurogenic bladder, conversion to open surgery and morbidity have been observed probably due fact that we didn't ligate fistula instead cauterized it, this could also explain some damage to vesical neural plexus. Conversion to open conventional technique has been more due to lack of laparoscopic trained staff, inadequate facilities and learning curve we are going through which could also explain increased morbidity in our study.

In the present study, functional outcome of patients was defined according to Kelly's clinical score. The information concerning fecal incontinence and fecal staining was gained from children's parents and digital rectal examination. Mean KCS was observed to be 3.75 \pm 0.68. Half of the patients $(50 \%)$ were assigned Kelly's clinical score of 4 , followed by $25 \%$ with $\mathrm{K} 5$ and $25 \%$ with K3. Tong et al, ${ }^{11}$ in their study observed mean KCS as 3.52 \pm 1.42 . Constant staining/smearing and soiling/accidental defecation after LAARP was observed in 2 patients each respectively. Also, 1 patient each had constant bout of constipation and diarrhoea. 8 patients were observed with occasional staining/smearing and 6 patients with soiling or accidental defection. 4 patients 
had occasional constipation and 1 patient had diarrhoea. On digital rectal examination 7 patients had strong anal sphinteric tone, 6 patients had weak anal sphenteric tone and 3 patients had no anal sphinteric tone.

Table 16: Comparison of Kellys score.

\begin{tabular}{|ll|}
\hline Tong et $\mathrm{al}^{11}$ & $3.52 \pm 1.42$ \\
\hline Present study & $3.75 \pm 0.68$ \\
\hline
\end{tabular}

Mean Kelly's clinical score done after 2 years of surgery was higher in present study as compared to other study. This could be due to the fact that subjective variation can occur on digital rectal examination for sphincter tone. Moreover parental judgement of faecal staining and smearing could vary, leading to exaggerated score

\section{CONCLUSION}

On the basis of observations made and their analysis it might be concluded that laparoscopy-assisted anorectoplasty is anatomically sound. There is minimal perenial dissection, no division of muscle complex, excellent visualization of rectal fistula and surrounding structures, preservation of distal rectum and accurate placement of rectum within levator ani and external anal sphincteric muscle complex. There is shorter hospital stay with better functional outcome. However Intraoperative complication, Operative time and conversion to open surgery is relatively high, most of which can be attributed to a 'learning curve' and improper patient selection which should not be discouraging for training residents to undertake such procedures at teaching institutes.

However Long-term follow-up for continence is needed for further evaluation of this technique and to establish it as an alternative to conventional surgery.

\section{ACKNOWLEDGEMENTS}

We are thankful to the Head of Department of Paediatric Surgery, BHU, Varanasi. We are also thankful to the staffs of Department of Paediatric Surgery and Medical Records Department for their support throughout the study.

Funding: No funding sources

Conflict of interest: None declared

Ethical approval: The study was approved by the institutional ethics committee

\section{REFERENCES}

1. Pena A, Hong A. Advances in the management of anorectal malformations. Am J Surg. 2000;180:3706.
2. Santulli TV. The treatment of imperforate anus and associated fistulas. Surg Gynecol Obstet. 1952;95:601-14.

3. Al-Hozaim O, Al-Maary J, Al-Qahtani A, Zamakhshary M. Laparoscopic-assisted anorectal pull-through for anorectal malformations: a systematic review and the need for standardization of outcome reporting. J Pediatr Surg. 2010;45:15004.

4. Willital GH. Endosurgical intrapuborectal reconstruction of high anorectal anomalies. Pediatr Endosurg Innov Tech. 1998;2:5-11.

5. Elbarbary MM, Fares AE, Saket HE. Laproscopically assisted anorectoplasty: A new definitive repair of high imperforate anus. Annals of Pediatric Surgery. 2008;4:1-7.

6. Bhandary KS, Kumaran V, Rajamani G. Laproscopic assisted anorectal pull through: reformed techniques. J Indian Assoc Pediatr Surg. 2009;14:210-4.

7. Kudou S, Iwanaka T, Kawashima H. Midterm follow-up study of high-type imperforate anus after laproscopically assisted anorectoplasty. J Pediatr Surg. 2005;40:1923-6.

8. Georgeson KE, Inge TH, Albanese CT. Laproscopically assisted anorectal pull-through for high imperforate anus - a new technique. J Pediatr Surg. 2000;35:927-31.

9. Iwai N, Fumino S. Surgical treatment of anorectal malformations. Surg Today. 2013;43:955-62.

10. Shandip S, Ravi PK, Ashish W. Delayed presentation of anorectal malformations. J Indian Assoc Pediatr Surg. 2008;13:64-8.

11. Tong QS, Tang ST, Pu JR. Laproscopically assisted anorectal pull-through for high imperforate anus in infants: intermediate results. J Pediatr Surg. 2011;46:1578-86.

12. Jung SM, Lee SK, Seo JM. Experience with laparoscopic-assisted anorectal pull-through in 25 males with anorectal malformation and rectourethral or rectovesical fistulae: postoperative complications and functional results. J Pediatr Surg. 2013;48:5916.

13. De Vos C, Arnold M, Sidler D, Moore SW. A comparison of laparoscopic-assisted (LAARP) and posterior sagittal (PSARP) anorectoplasty in the outcome of intermediate and high anorectal malformations. S Afr J Surg. 2011;14,49(1):39-43.

14. Stephens FD, Smith ED. Anorectal Malformations in Children. Chicago: Year Book Medical Publishers. 1971.

15. Rintala R, Lindahl H, Louhimo I. Anorectal malformations - results of treatment and long term follow-up of 208 patients. Pediatr Surg Int. 199I;6:36-41.

16. Iwanaka T, Arai M, Kawashima H. Findings of pelvic musculature and efficacy of laparoscopic muscle stimulator in laparoscopy assisted anorectal pull-through for high imperforate. Surg Endosc. 2003; 17:278-81.

17. Ming AX, Li L, Diao M, Wang HB, Liu Y, Ye M. Long term outcomes of laparoscopic-assisted anorectoplasty: a comparison study with posterior sagittal anorectoplasty. J Pediatr Surg. 2014;49(4):560-3.

Cite this article as: Raina S, Jad B, Kumar V, Sharma SP, Kumar N. Laparoscopic assisted anorectoplasty in children: a prospective study. Int Surg J 2016;3:162-8. 